\title{
THE VALUE OF CARING
}

\section{A REPLY TO MAGUIRE}

\author{
Jörg Löschke
}

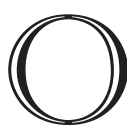

NE STANDARD OBJECTION against classical act consequentialism is that it cannot justify partiality to our loved ones. Classical act consequentialism claims that agents are always required to bring about the impersonally best outcome, or, to put it in more technical terms, that an agent is required to do what she has most reason to do, and that the strength of a reason for action is a function of the value that the action would bring about. The more value an action would realize, the stronger the reason to perform that action, and the action that maximizes value is therefore always supported by the strongest reasons. And classical act consequentialism understands value as agent-neutral value: the goodness of an outcome does not depend on the point of view or the identity of the agent. Agents are therefore not permitted to attach special significance to their own personal relationships when they deliberate about what to do. Of course, relationships might be impersonally valuable, and a world with loving relationships might be better than a world without such relationships. If that is true (and it is plausible to assume that it is), then agents must take the value of relationships into account when they deliberate about what to do. But on an agent-neutral understanding of value, this just means that they are required to regard their own relationships as just as valuable as the relationships of other people. The fact that some relationship is mine bears no special significance. ${ }^{1}$

To illustrate this point, consider the following example that has been put forward by Barry Maguire:

Angela and Becca both love their mothers. Angela's mother is a beneficent soul, always doing her best to improve the lives of those around her. Becca's mother is rather self-centered, and never really thinks about

1 For different formulations of the criticism that consequentialism cannot accommodate partiality to loved ones, see, among others, McNaughton and Rawling, "Honoring and Promoting Value"; Jollimore, Friendship and Agent-Relative Morality; Card, "Consequentialism, Teleology, and the New Friendship Critique"; and Wallace, "Reasons, Values and Agent-Relativity." 
or does much for others. Alas, the two mothers are stuck in a burning building. There is only one oxygen mask; only one daughter can save her mother. Becca is holding the mask.... Becca is in a position either to save her mother or enable Angela to save Angela's slightly more beneficent mother. $^{2}$

If agents are always required to bring about the agent-neutrally best outcome, then Becca ought to enable Angela to save Angela's mother. After all, given Angela's mother's character, her surviving would be better from an impersonal point of view. And Angela has the same kind of valuable relationship with Angela's mother as Becca has with Becca's mother, so there is no reason why classical consequentialism should permit Becca to favor her own mother, due to their valuable relationship. However, most people probably share the intuition that Becca ought to save her own mother rather than enable Angela to save Angela's mother. The question is whether consequentialism can accommodate this intuition without sacrificing its core commitments: the agent-neutral conception of value, the teleological conception of reasons (according to which practical reasons are reasons to bring about valuable states of affairs), and the maximizing view (according to which agents are required to bring about the impersonally best outcome).

Authors with consequentialist leanings have responded to this challenge from partiality in different ways. ${ }^{3}$ However, all of these attempts have met criticism. ${ }^{4}$ An interesting new attempt to justify partiality within a consequentialist framework has been recently put forward by Barry Maguire.

Maguire's crucial move is to claim that the strength of an agent's reason to bring about an outcome can be modified by the (agent-neutral) value of the agent's caring about that outcome. ${ }^{5}$ It is good that Becca cares about the out-

2 Maguire, "Love in the Time of Consequentialism," 4.

3 Some authors abandon the agent-neutral conception of value and adopt an agent-relative conception of value instead. See, for example, Smith, "Neutral and Relative Value After Moore" and "Two Kinds of Consequentialism," or Portmore, Commonsense Consequentialism: Wherein Morality Meets Rationality. Others reject the view that agents are always required to bring about the best possible outcome and adopt a satisficing view, according to which agents are required to bring about outcomes that are sufficiently good. See, for example, Slote, "Satisficing Consequentialism" and Common-Sense Morality and Consequentialism, or Vallentyne, "Against Maximizing Act-Consequentialism."

4 For objections against the strategy to rely on agent-relative value, see Schroeder, "Teleology, Agent-Relative Value, and 'Good," or Cullity, "Neutral and Relative Value." For problems of satisficing consequentialism, see Mulgan, "Slote’s Satisficing Consequentialism,” or Bradley, "Against Satisficing Consequentialism."

5 Maguire, "Love in the Time of Consequentialism," 10. 
come in which her mother survives, and this means that the state of affairs [Becca's mother survives, and Becca cares about it] is agent-neutrally better than the state of affairs [Angela's mother survives] or the state of affairs [Angela's mother survives, and Becca cares about it]. ${ }^{6}$ Becca's reason to save her own mother is therefore stronger than her reason to enable Angela to save Angela's mother, even if Angela's mother surviving is the agent-neutrally better outcome, compared to Becca's mother surviving. And since Becca's reason to save her own mother is stronger than her reason to enable Angela to save Angela's mother, Becca ought to save her own mother.

This proposal is interesting, but it fails to justify partiality within a consequentialist framework because it does not explain the special normative significance of an agent's caring attitude for that agent. Or so I will argue.

To see why Maguire's proposal does not succeed, we can imagine that Becca is a convinced consequentialist and tries to figure out what she ought to do when she faces the choice of either saving her own mother or enabling Angela to save Angela's mother instead. Becca knows that it would be impersonally better if Angela's mother survived, but she also knows that it is good for participants in personal relationships to care about each other-she knows, in other words, that there is value in her caring about the outcome in which her own mother survives. So Becca might deliberate as follows:

I can either save my own mother, or enable Angela to save Angela's mother. The survival of my own mother and the survival of Angela's mother are both valuable outcomes, so I have reason to bring about either one of them. But Angela's mother is a beneficent soul, and my own mother is rather self-centered. That means that, from an impersonal point of view, it would be better if Angela's mother survives, and I have more reason to enable Angela to save Angela's mother. However, I care about the outcome in which my own mother survives-much more than I care about the

6 Maguire does not put his view in terms of such states of affairs. However, it is natural to interpret him in this way. According to Maguire, the bearers of value are states of affairs. The value of caring about an outcome must therefore also be understood as a valuable state of affairs. Furthermore, Maguire understands the weight of a reason as "a monotonically increasing function of the value of its object state, perhaps along with other variables" ("Love in the Time of Consequentialism," 4). It is therefore plausible to assume that Becca's reason to save her own mother increases in strength due to this additional value in the more finegrained description of the relevant state of affairs [Becca's mother survives, and Becca cares about it], compared to [Becca's mother survives]. 
survival of Angela's mother. And clearly, it is good if children care about their parents in the way that I care about my mother. And my caring about my mother is good not only from my point of view, but agent-neutrally good. So I have to take this value into account when I decide what to do. I do not have to compare [Angela's mother survives] and [Becca's mother survives], but [Angela's mother survives] and [Becca's mother survives, and Becca cares about it]. And if I compare these states of affairs, the additional agent-neutral value of my caring about the outcome in which my mother survives makes a difference; it makes [Becca's mother survives, and Becca cares about it] agent-neutrally better than [Angela's mother survives]. It therefore increases the strength of my reason to save my own mother. My reason to save my own mother is stronger than my reason to enable Angela to save Angela's mother-so I ought to save my own mother, rather than enable Angela to save Angela's mother.

At this point, the problem for Maguire's proposal emerges. Maguire accepts that all value is agent-neutral value. ${ }^{7}$ He therefore accepts that Becca's caring attitude is agent-neutrally good, and that [Becca's mother survives, and Becca cares about it] is also agent-neutrally good. Agent-neutrally good states of affairs give all agents reason to promote them-this is consequentialism's interpretation of impartiality, and it is sometimes taken to be an attractive feature of the theory. ${ }^{8}$ This means that not only Becca but also Angela has reason to bring about [Becca's mother survives, and Becca cares about it]. And importantly, it also means that Becca has reason to bring about [Angela's mother survives, and Angela cares about it], since that state of affairs is also agent-neutrally good. We therefore have to compare not the agent-neutral value of [Becca's mother survives, and Becca cares about it] and [Angela's mother survives] but the agent-neutral value of [Becca's mother survives, and Becca cares about it] and [Angela's mother survives, and Angela cares about it].

The problem is that the agent-neutral value of [Angela's mother survives, and Angela cares about it] should be greater than the agent-neutral value of [Becca's mother survives, and Becca cares about it]. Angela's mother surviving is agent-neutrally better than Becca's mother surviving, and there is no reason to think that Becca's caring attitude toward her mother is agent-neutrally better than Angela's caring attitude toward Angela's mother. So if we add the agent-neutral value of the respective caring about the outcome to the agent-neutral value of the respective outcome, we still get the result that [Angela's mother survives,

7 Maguire, "Love in the Time of Consequentialism," 3.

8 See, for example, McElwee, "Impartial Reasons, Moral Demands," 458. 
and Angela cares about it] has more agent-neutral value than [Becca's mother survives, and Becca cares about it]. Becca has therefore more reason to bring about the first outcome than she has reason to bring about the second outcome, and that means that she ought to enable Angela to save Angela's mother rather than save her own mother. The value of her caring attitude cannot justify partiality within an agent-neutral consequentialist framework.

Note that this argument does not rely on any specific account of how the value of an agent's caring about an outcome can modify the strength of her reason to bring that outcome about. It does not matter whether we think that the value of an agent's caring about an outcome must be added to the value of that outcome, or if we think that the modification works in some other way. ${ }^{9}$ Once we assume that it is the agent-neutral value of my caring about an outcome that modifies the strength of my reason to bring about that outcome, we need an argument for why the agent-neutral value of some other agent's caring about a different outcome does not change my normative situation as well. And as far as I can see, Maguire does not provide such an argument.

One might argue that there is an important difference between $m y$ caring about a specific outcome and your caring about a different outcome: the first caring attitude is mine, and the second is not. One might think that this difference is relevant, and that the value of Becca's caring about a specific outcome modifies the strength of Becca's reason to bring about that outcome, while the value of Angela's caring about a specific outcome modifies the strength of Angela's reason to bring about that outcome, and so on. In this view, the value of Becca's caring attitude is normatively relevant only for Becca and not for Angela, and the value of Angela's caring attitude is normatively relevant only for Angela but not for Becca. It would then follow that Becca ought to save her own mother rather than enable Angela to save Angela's mother, because the weight of Becca's reason to save her own mother is modified in a way that the strength of her reason to enable Angela to save Angela's mother is not. ${ }^{10}$

But what should explain this normative specialness of my caring attitude for

9 At one point ("Love in the Time of Consequentialism," 7), Maguire suggests that the strength of a reason is modified by adding the value of the agent's caring about an outcome to the value of that outcome. Later ("Love in the Time of Consequentialism," 14), Maguire seems to suggest that the modification works in some other way, without going into detail of how the modification works.

This is what Maguire seems to have in mind when he writes, "The trick is that the partial orientations we are evaluating are the agent's own. We are not evaluating, for instance, the agent's partial orientation towards some states of affairs and someone else's partial orientation towards some state of affairs. It is plausibly of value to be partially oriented towards some outcomes rather than others. This is what makes it possible-even though our expla- 
$m e$ ? In an earlier presentation of the account, Maguire explains the normative specialness of an agent's caring attitude for that agent by arguing that

attitudes always consist in a relation between an agent and a state of affairs. The agent herself cannot but stand in the first place of this relation. States of affairs consisting in some agent standing in an attitudinal relation to some other state of affairs are regular old states of affairs like any other, and admit of some neutral value or disvalue just like any other. However they are in one important and non-axiological sense agent-relative, simply because the agent cannot remove herself from the first relatum. It is metaphysically impossible for me to have your attitudes, or you mine. ${ }^{11}$

Maguire seems to explain the normative specialness of $m y$ caring attitude by its descriptive specialness: my attitude is agent-relative in a descriptive way and, from this descriptive specialness, Maguire infers that it is also agent-relative in a normative way. In other words, he seems to assume that, from the fact that $m y$ caring attitude cannot be anyone else's attitude but mine, it follows that my caring attitude cannot be normatively relevant for anyone but $m e$.

Of course, it is true that an attitude is agent-relative in the sense that its existence depends on the agent who has that attitude. Becca can only have Becca's attitudes, and Angela can only have Angela's attitudes. But it does not follow that Becca's attitudes are agent-relative in a normative way as well, and that they are relevant only for Becca, or that Angela's attitudes are agent-relative in a normative way and are relevant only for Angela. The claim that an agent's attitudes are agent-relative in the descriptive sense does not entail that they are also agent-relative in a normative sense.

To see this, consider the case of pain. Pain is also agent-relative in a descriptive sense. The existence of pain depends on the agent who experiences the pain, and I can only experience $m y$ pain, not yours, whereas you can only experience your pain, not mine. But that does not mean that my pain is normatively relevant only for me. My pain is bad, not only from my point of view but also in an agent-neutral sense (the badness of my pain does not depend on the fact that $I$ am the one who experiences it), and other agents have reason to alleviate my pain if they are in a position to do so. Thus, the fact that my pain is agent-relative in a descriptive sense does not show that it is also agent-relative in a normative sense, and that it affects only my normative situation. Descriptive agent-relativity does not translate into normative agent-relativity. Accordingly, there is no rea-

nantia are all neutral values - that agents may have more reason to bring about those states of affairs." ("Love in the Time of Consequentialism," 10)

Maguire, "Values, Reasons, and Ought," 58. 
son to think that the fact that my caring attitude cannot be anyone else's attitude but mine entails that my attitude only affects my normative situation, or that it modifies only the strength of my reasons.

One possible alternative is to ground the intensifying role of an agent's caring attitudes not in the value of those attitudes but in their actual occurrence, without saying anything about their value. In that case, it would not be obvious that the caring attitudes of an agent are normatively relevant for other agents-after all, it is the fact that the value of an agent's attitudes is doing the reason-modifying work that leads to the question of why the (agent-neutral) value of my attitudes does not modify your reasons as well. And it would also explain why the descriptive specialness of my attitudes translates into a normative specialness. The problem with this solution, however, is that it would rob the account of much of its plausibility. It would imply that an agent's actual caring about silly or evil outcomes modifies her reasons so that she possibly has most reason to perform silly or evil acts. It would also imply that Becca has more reason to enable Angela to save Angela's mother if, for some reason, Becca just does not care about the survival of her own mother. ${ }^{12}$ Maguire's view is supposed to explain commonsense intuitions, and one of these intuitions is that Becca does have more reason to save her own mother, even if she does not care about her mother's survival. Every other claim would appear overly subjectivist.

Maguire's proposal faces a dilemma. Either he grounds the reason-modifying role of caring attitudes in their actual occurrence, rather than their value, in which case Becca has no more reason to save her own mother than to enable Angela to save Angela's mother if Becca simply does not care about the survival of her own mother. Or he grounds the reason-modifying role of an agent's caring attitudes in the value of those attitudes. He can then claim that Becca has more reason to save her own mother, even if she does not care about her mother's survival, because it would be good if she did care about her mother's survival. This, however, means that the value of a caring attitude can modify an agent's reasons, even if that agent does not have that attitude. This leads to the question of why the value of Angela's attitudes does not modify Becca's reasons also. Sure, Becca cannot have Angela's attitudes, but if the value of an attitude can modify an agent's reasons, even if the agent does not have that attitude, we need further explanation of why this does not also apply to the value of the attitudes of other 
persons. As interesting as Maguire's proposal is, a convincing justification of partiality within a consequentialist framework is still pending. ${ }^{13}$

\author{
University of Bern \\ joerg.loeschke@philo.unibe.ch
}

\title{
REFERENCES
}

Bradley, Ben. “Against Satisficing Consequentialism.” Utilitas 18, no. 2 (June 2006): 97-108.

Card, Robert F. "Consequentialism, Teleology, and the New Friendship Critique." Pacific Philosophical Quarterly 85, no. 2 (June 2004): 149-72.

Cullity, Garrett. "Neutral and Relative Value." In The Oxford Handbook of Value Theory, edited by Iwao Hirose and Jonas Olson, 96-116. Oxford: Oxford University Press, 2015.

Jollimore, Troy. Friendship and Agent-Relative Morality. New York: Garland Publishing, 2001.

Maguire, Barry. "Love in the Time of Consequentialism." Noûs. Published electronically August 25, 2016. doi:10.1111/nous.12169.

- "Values, Reasons, and Ought." PhD diss., Princeton University, 2012.

McElwee, Brian. "Impartial Reasons, Moral Demands." Ethical Theory and Moral Practice 14, no. 4 (August 2011): 457-66.

McNaughton, David, and Piers Rawling. "Honoring and Promoting Value." Ethics 102, no. 4 (July 1992): 835-43.

Mulgan, Tim. "Slote's Satisficing Consequentialism." Ratio 6, no. 2 (December 1993): 121-34.

Portmore, Douglas W. Commonsense Consequentialism: Wherein Morality Meets Rationality. New York: Oxford University Press, 2011.

Schroeder, Mark. "Teleology, Agent-Relative Value, and 'Good.” Ethics 117, no. 2 (January 2007): 265-95.

Slote, Michael. Common-Sense Morality and Consequentialism. London: Routledge, 1985 .

- "Satisficing Consequentialism." Proceedings of the Aristotelian Society, Supplementary Volumes 58 (1982): 139-64.

13 This work was supported by the Swiss National Science Foundation (SNSF) through the research project “The Normative Significance of Agent-Relative Reasons" (Grant 100012-152918). I would like to thank an anonymous referee for very helpful comments on an earlier version of this paper. 
Smith, Michael. "Neutral and Relative Value After Moore," Ethics 113, no. 3 (April 2003): 576-98.

."Two Kinds of Consequentialism." Philosophical Issues 19 (October 2009): 257-72.

Vallentyne, Peter. “Against Maximizing Act-Consequentialism." In Contemporary Debates in Moral Philosophy, edited by James Dreier, 21-37. Malden: Blackwell Publishing, 2006.

Wallace, R. Jay. "Reasons, Values and Agent-Relativity," Dialectica 64, no. 4 (December 2010): 503-28. 